\title{
Article \\ Reconstruction of Rice Drying Model and Analysis of Tempering Characteristics Based on Drying Accumulated Temperature
}

\author{
Yi Jin $\left.{ }^{1}{ }^{(}\right)$, Jun Yin ${ }^{1}$, Huihuang $X_{i e}{ }^{2}$ and Zhongjie Zhang ${ }^{1, *}$ \\ 1 National Engineering Laboratory for Grain Storage and Transportation, Academy of National Food and \\ Strategic Reserves Administration, Beijing 100037, China; jinyijlu@163.com (Y.J.); yjun@ags.ac.cn (J.Y.) \\ 2 Jiangsu Key Laboratory of Advanced Food Manufacturing Equipment and Technology, \\ College of Mechanical Engineering, Jiangnan University, Wuxi 214122, China; \\ 6200810104@stu.jiangnan.edu.cn \\ * Correspondence: zzj@ags.ac.cn
}

check for updates

Citation: Jin, Y.; Yin, J.; Xie, H.; Zhang, Z. Reconstruction of Rice Drying Model and Analysis of Tempering Characteristics Based on Drying Accumulated Temperature. Appl. Sci. 2021, 11, 11113. https:// doi.org/10.3390/app112311113

Academic Editor: Claudio Medana

Received: 22 October 2021

Accepted: 22 November 2021

Published: 23 November 2021

Publisher's Note: MDPI stays neutral with regard to jurisdictional claims in published maps and institutional affiliations.

Copyright: (c) 2021 by the authors. Licensee MDPI, Basel, Switzerland. This article is an open access article distributed under the terms and conditions of the Creative Commons Attribution (CC BY) license (https:/ / creativecommons.org/licenses/by/ $4.0 /)$.

\begin{abstract}
Previous research has shown that the accumulated temperature can describe drying processes as well as crop growth. To describe the mass and heat transfer processes in the rice drying process more accurately, a mathematical model of rice drying was proposed based on the drying accumulated temperature, and the optimal tempering ratio for conventional hot air drying was obtained through data comparison and analysis. First, it was proven that there was an exponential relationship between the moisture ratio and the drying accumulated temperature of rice. Second, by comparing and analyzing the fitting results of seven different drying mathematical models, the model with the highest fitting degree was selected and reconstructed to obtain the drying accumulated temperature-moisture ratio model. Finally, the new model was used to fit the results of two drying experiments without and with tempering, and the tempering characteristics of rice drying were proved by comparing and analyzing the coefficient difference between the two models. The results showed that the optimal tempering ratio was 3 . This study thus provides a reference for rice drying process parameters.
\end{abstract}

Keywords: drying accumulated temperature; moisture ratio; rice; tempering

\section{Introduction}

Drying is a heat and mass transfer process that involves moisture migration, moisture diffusion, a large evaporation lag time, strong coupling of the drying parameters, and non-linear effects. Drying is not only affected by the physical structures and the chemical properties of the materials; it also is related to the climatic conditions and the drying process [1]. Mathematical modeling can be used to explore the relationships between the parameters in a system, and these relationships can be quantified and finally described in the form of mathematical language. In addition, the model can be used to calculate and analyze the relationships between various parameters or trends of the whole data set [2]. During the drying of grains, the appearance, nutrient composition, and chemical composition of the grains varies, and many of these variations can be modeled as functions of temperature, moisture, and time [3]. Therefore, if the dependence of the temperature and moisture content distribution in the grain on the drying time can be established accurately, adverse effects can be better predicted and controlled [4,5]. To establish a mathematical model of grain drying that is more practical and can be used in dryers, it is necessary to consider the complicated heat and mass transfer processes. This process is related to many factors, such as the temperature, humidity, and wind speed, and it is often affected by many at the same time [6]. Most of these factors have non-linear characteristics and large lags in terms their effects on the drying process. Furthermore, some factors are difficult to measure, such as the density of a grain pile in the dryer and its effect on the drying process. Therefore, many current mathematical models are more scientific than practical. 
To improve the above situation, many new and more accurate sensors and gauges have been introduced in recent years to record more comprehensive data or enhance control systems, which makes building new models more challenging [7]. The Page model [8], proposed by Page in 1949, has had a profound influence on field of drying. The Lewis model [9] is an exponential model that is also widely used in the field of drying, which uses Newton's law of cooling to describe moisture motion. The Midilli model [10] is another exponential model, which has a better fitting effect than the Page model in some cases. Prakash [11] proposed two single-parameter equations to quantify the thin-layer drying characteristics of contemporary long-grain rice cultivars grown in the Mid-South U.S. The results showed that the two equations have a high degree of fitting, with the shortcoming that only two drying parameters, hot air temperature and relative humidity, were taken as the influencing factors. Chen, et al. [12] carried out an orthogonal experiment involving hot air drying with variable temperature and humidity and established a comprehensive target model; the drying process was optimized by a genetic algorithm. Alves Pereira, et al. [13] used empirical and diffusion models to describe rice drying kinetics, and considered only effective time of operation to compare and evaluate continuous and intermittent drying of rough rice. This study proved that a one-dimensional diffusion model could describe the drying process of rice properly, and found that the effective mass diffusivity was higher in intermittent drying as compared to continuous drying at the same temperature. The models established in the above studies can describe the grain drying process to a certain extent; however, there is still room for improvement in the model accuracy.

Rice is a kind of heat sensitive material which requires a high drying process $[6,14]$. Intermittent drying is used in conventional rice drying around the world; it is considered one of the solutions to improve the energy efficiency and post-drying quality of rice without increasing drying cost, and has good research and promotional prospects. This technique reduces possible damage in the form of cracks, minimizes energy costs, and provides better final product quality [15]. The most common form of intermittent drying is alternating drying and tempering. Tempering refers to placing rice in a relatively confined space for a period of time without human intervention in order to balance the moisture gradient and reduce thermal stress between grains and within grains [16,17]. After tempering, moisture is redistributed so that surface moisture can be removed more easily, thus increasing the drying rate. In addition, moisture and heat gradients are reduced, which greatly reduces heat and moisture stress and physical damage to the rice so as not to destroy its structure [18]. Golmohammadi, et al. [19] developed a two-part mathematical model to describe the moisture distribution of rice during drying and tempering, and proposed an analytical solution model based on Fick's second diffusion law. In his conclusion, he also stated that the tempering process greatly reduced drying energy consumption. Cihan, et al. [20] studied a variety of mathematical models for describing the intermittent drying properties of rough rice and found that the coefficient $a$ and $b$, drying coefficient $k$ and exponent $n$ in the Midilli model can be expressed as a polynomial function of tempering time. In the research of Dong, et al. [21], it was shown that the tempering time and temperature in the drying process had significant effects on the rice moisture gradient and the crack rate. Zhou, et al. [16] respectively provided the optimal tempering ratio of infrared radiation and heat pump drying on long-grain rice, which was 2 for infrared radiation drying and 3 for heat pump drying.

In this paper, it is proposed that the accuracy of these models can be improved by the introduction of a new parameter, the effective accumulated drying temperature. Many studies have proven that the concept of an accumulated temperature in agronomy can be used to describe the grain drying process [22]. In our previous studies [23], we found that under certain drying conditions, the accumulated temperature required for grain moisture to reach the safe level is a relatively stable quantity. Therefore, based on the concept of the effective drying accumulated temperature, a mathematical model of grain drying was constructed in order to describe the grain drying process from a new perspective and to improve the grain drying model accuracy. On this basis, by comparing the mathematical 
model obtained in the previous experiment with the one established in this experiment, the difference between the two coefficients was analyzed and the physical significance of the data was revealed; finally, the optimal tempering ratio of rice drying was obtained. This method can also be used in drying research on other varieties of grain.

\section{Theory and Model Derivation}

\subsection{Effective Drying Accumulated Temperature Theory}

Previous studies have fully proven that the temperature, especially the accumulated temperature, plays a vital role in ensuring seed germination [24-26], ensuring vegetation growth and distribution [27], increasing crop yield [28], and reducing insect pests [29]. Agronomists and meteorologists began to use an integral method to calculate the accumulated temperature in the 1950s. The temperature changes with time were plotted, and the following formulae were respectively proposed to calculate the active accumulated temperature and effective accumulated temperature [30]:

$$
\begin{gathered}
A_{n}=\int_{t_{0}}^{t_{n}} T(t) d t \quad T(t) \geq T_{0} ; \text { if } T(t)<T_{0}, T(t)=0, \\
A_{e}=\int_{t_{0}}^{t_{n}}\left[T(t)-T_{0}\right] d t \quad T(t) \geq T_{0} ; \text { if } T(t)<T_{0}, T(t)-T_{0}=0,
\end{gathered}
$$

where $A_{n}$ is the active accumulated temperature $\left({ }^{\circ} \mathrm{C} \cdot \mathrm{d}\right), A_{e}$ is the effective accumulated temperature $\left({ }^{\circ} \mathrm{C} \cdot \mathrm{d}\right), t_{0}$ is the initial time, $t_{n}$ is the final time, and $T_{0}$ is the biological zero degree $\left({ }^{\circ} \mathrm{C}\right)$.

The biological zero degree is defined as the lower temperature limit for plant growth and development under suitable conditions. Correspondingly, there is an equilibrium temperature in the grain drying process; that is, drying will begin only when the temperature is higher than the equilibrium temperature without considering other environmental factors. In this paper, the effective drying accumulated temperature of the grain (hereinafter referred to as drying accumulated temperature) is defined as the sum of the temperatures higher than the equilibrium temperature of the grain in the drying process, expressed as follows:

$$
A T=\int_{0}^{t_{n}}\left[T-T_{e}\right] d t
$$

where $A T$ is the accumulated effective drying temperature of the grain $\left({ }^{\circ} \mathrm{C} \cdot \mathrm{h}\right), T$ is the temperature of the grain at time $t\left({ }^{\circ} \mathrm{C}\right), T_{e}$ is the desorption equilibrium temperature of grain at time $t\left({ }^{\circ} \mathrm{C}\right)$, and $t_{n}$ is the drying time $(\mathrm{h}) . T_{e}$ can be derived from the modified Chung-Pfost equation (MCPE) [31,32]:

$$
R H=\exp \left[-\frac{C_{1}}{T_{e}+C_{2}} \exp \left(-C_{3} \times M_{e}\right)\right] .
$$

The equilibrium temperature is expressed as follows:

$$
T_{e}=-\frac{C_{1}}{\ln (R H)} \exp \left(-C_{3} \times M_{e}\right)-C_{2} .
$$

In these equations, $R H$ is the relative humidity (decimal), $M_{e}$ is the equilibrium moisture content (\%, dry basis), and $C_{1}, C_{2}$, and $C_{3}$ are constants that depend on the crop variety. The research object of this paper was rice, and the corresponding constants are as follows: $C_{1}=529.276, C_{2}=52.725$, and $C_{3}=0.177$ [32].

The formula of the equilibrium moisture content of the grain is as follows:

$$
M_{e}=-\frac{1}{N_{3}} \times \ln \left[-\frac{\left(T_{r}+N_{2}\right) \times \ln (R H)}{N_{1}}\right],
$$


where $T_{r}$ is the relative temperature $\left({ }^{\circ} \mathrm{C}\right)$, and $N_{1}, N_{2}$, and $N_{3}$ are constants that depend on the crop variety. The constants for rice are as follows: $N_{1}=588.376, N_{2}=59.026$, and $N_{3}=0.18$ [32].

The equilibrium temperature as a function of the moisture content and environmental relative humidity can obtained using Equation (5), and the obtained equilibrium temperatures are plotted in Figure 1. The higher the moisture content of the rice is, the lower the desorption equilibrium temperature of the rice is. The higher the environmental relative humidity is, the higher the desorption equilibrium temperature of the rice is. For a fixed moisture content of the rice, the desorption temperature increases significantly with the increase in the relative humidity of the environment. For a fixed environmental relative humidity, the moisture content of rice is negatively correlated with the desorption equilibrium temperature. When the relative humidity is lower than $40 \%$ and the moisture content of rice is higher than $13.5 \%$, the desorption equilibrium temperature of the rice is lower than $0{ }^{\circ} \mathrm{C}$.

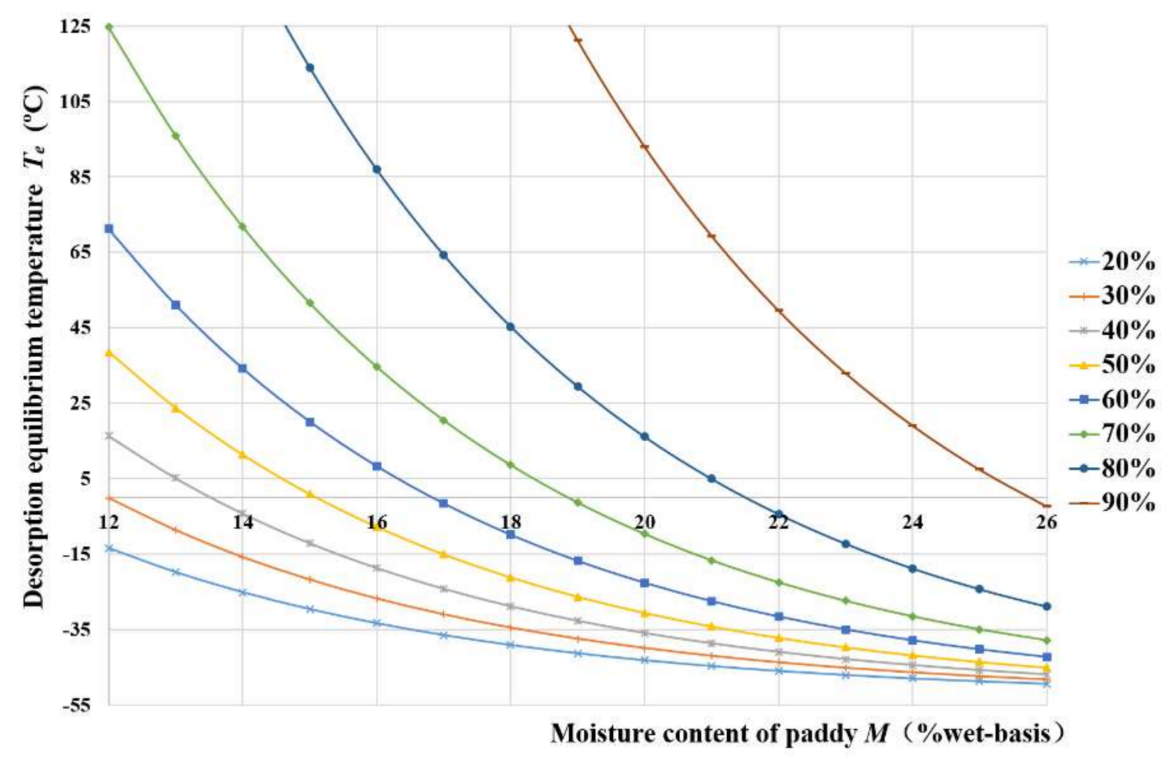

Figure 1. Relationship between the moisture content of rice and the desorption equilibrium temperature under different relative humidities.

\subsection{Derivation of Effective Drying Accumulated Temperature Model for Rice}

In the previous orthogonal test, the temperature of the rice sample was roughly equal to the temperature of the hot air. This is because the test equipment used was in the form of hot air internal circulation, so the grain temperature was approximately regarded as hot air temperature to reduce unnecessary calculation. Therefore, Equation (3) was simplified to obtain the following formula for the drying accumulated temperature of rice:

$$
A T_{n}=\sum_{i=1}^{n}\left(T-T_{e i}\right) \times t_{i}
$$

where $t_{i}$ is the time of the $i$ th weighing cycle ( $t_{i}=0.25 \mathrm{~h}$ in this experiment), and $T_{e i}$ is the desorption equilibrium temperature of rice in the $i$ th weighing cycle $\left({ }^{\circ} \mathrm{C}\right)$. The formula for $T_{e i}$ is as follows:

$$
T_{e}=-\frac{C_{1}}{\ln (R H)} \exp \left(-C_{3} \times M_{i}\right)-C_{2},
$$

where $M_{i}$ is the initial moisture content of the rice in the $i$ th weighing cycle (\%, dry basis).

To establish a mathematical model of the relationship between the moisture ratio and drying accumulated temperature, the moisture ratio and accumulated temperature during different drying stages were compared, as shown in Table 1. 
Table 1. Calculation method of moisture ratio and drying accumulated temperature.

\begin{tabular}{cccc}
\hline$M R$ & Calculation Method & $A T$ & Calculation Method \\
\hline$M R_{0}$ & 1 & $A T_{0}$ & 0 \\
$M R_{1}$ & $\frac{M_{d 1}-M_{e}}{M_{0}-M_{e}}$ & $A T_{1}$ & $\left(T_{1}-T_{e 1}\right) t_{1} 1$ \\
$M R_{2}$ & $\frac{M_{d 2}-M_{e}}{M_{0}-M_{e}}$ & $A T_{2}$ & $\left(T_{1}-T_{e 1}\right) t_{1}+\left(T_{2}-T_{e 2}\right) t_{2}$ \\
$M R_{3}$ & $\frac{M_{d 3}-M_{e}}{M_{0}-M_{e}}$ & $A T_{3}$ & $\left(T_{1}-T_{e 1}\right) t_{1}+\left(T_{2}-T_{e 2}\right) t_{2}$ \\
& & $\ldots$ & $+\left(T_{3}-T_{e 3}\right) t_{3}$ \\
$M R_{n}$ & $\frac{M_{d n}-M_{e}}{M_{0}-M_{e}}$ & $A T_{n}$ & $\left(T_{1}-T_{e 1}\right) t_{1}+\left(T_{2}-T_{e 2}\right) t_{2}$ \\
& & $\cdots+\left(T_{n}-T_{e n}\right) t_{n}$ \\
\hline
\end{tabular}

${ }^{1} T_{1}, T_{2}, \ldots, T_{3}$ are all hot air temperatures $T$ during thin layer drying $\left({ }^{\circ} \mathrm{C}\right)$, and $t_{1}, t_{2}, \ldots, t_{n}$ are the weighing cycles of the rice, which were each $0.25 \mathrm{~h}$ in this study.

The instantaneous wet-basis moisture content at each time node of each test group was extracted from the original test data, then was converted to dry-basis moisture content, $M_{d}$, as follows:

$$
M_{d}=\frac{M_{t}}{100-M_{t}} \times 100 .
$$

The moisture ratio of the rice sample at any time $\left(M R_{n}\right)$ can be determined by combining Equations (6) and (9).

The desorption equilibrium temperature $T_{e}$ during rice drying at each time node was different, because $T_{e}$ was related to its instantaneous dry-basis moisture content. The drying accumulated temperature can be obtained by combining Equations (5), (7) and (9). Equation (8) is combined with the simultaneous equations to obtain the total drying accumulated temperature $\left(A T_{n}\right)$ at any time node.

\section{Model Reconstruction}

\subsection{Test Review}

In the previous studies [23], a multiple quadratic regression orthogonal rotation combined experiment was carried out to explore the relationship between rice drying parameters and drying accumulated temperature. In the previous experiment, the hot air temperature $\left(X_{1}\right)$, the relative humidity of the hot air $\left(X_{2}\right)$, the initial moisture content of the rice $\left(X_{3}\right)$, and the velocity of the hot air $\left(X_{4}\right)$ were selected as the inputs, and the drying accumulated temperature was selected as the output. The level coding table of each factor in this experiment is shown in Table 2.

Table 2. Experimental factors and their levels.

\begin{tabular}{cccccc}
\hline Factor & \multicolumn{5}{c}{ Level } \\
\cline { 2 - 6 } & $\mathbf{- 2}$ & $\mathbf{- 1}$ & $\mathbf{0}$ & $\mathbf{1}$ & $\mathbf{2}$ \\
\hline Hot air temperature $\mathrm{X}_{1} /{ }^{\circ} \mathrm{C}$ & 27 & 31 & 35 & 39 & 43 \\
Relative humidity of hot air $\mathrm{X}_{2} / \%$ & 45 & 50 & 55 & 60 & 65 \\
Initial moisture content of rice $\mathrm{X}_{3} / \%$ & 17 & 19 & 21 & 23 & 25 \\
Velocity of hot air $\mathrm{X}_{4} / \mathrm{m} \mathrm{s}^{-1}$ & 0.4 & 0.5 & 0.6 & 0.7 & 0.8 \\
\hline
\end{tabular}

The test data were processed after the test. The moisture ratio and drying accumulated temperature were determined for each set of experimental conditions according to the method described in Section 2.2. The 18th group $\left(X_{1}=27^{\circ} \mathrm{C}, X_{2}=55 \%, X_{3}=21 \%\right.$, $X_{4}=0.6 \mathrm{~m} \mathrm{~s}^{-1}$ ) was randomly selected, and the results are shown in Table 3 . Test data were chosen randomly, as shown in Figure 2. There was an exponential relationship between the moisture ratio and the drying accumulated temperature during rice drying. Therefore, this relationship can be described by exponential equations. 
Table 3. Calculation results of moisture ratio and drying accumulated temperature.

\begin{tabular}{|c|c|c|c|c|c|c|}
\hline $\begin{array}{l}\text { Drying Time } \\
\text { (h) }\end{array}$ & $\begin{array}{l}\text { Wet-Basis } \\
\text { Moisture } \\
\text { Content (\%) }\end{array}$ & $\begin{array}{l}\text { Dry-Basis } \\
\text { Moisture } \\
\text { Content (\%) }\end{array}$ & $\begin{array}{c}\text { Desorption } \\
\text { Equilibrium } \\
\text { Temperature }\left({ }^{\circ} \mathrm{C}\right)\end{array}$ & $\begin{array}{c}\text { Real-Time Drying } \\
\text { Temperature Accumulation } \\
\left({ }^{\circ} \mathrm{C} \cdot \mathrm{h}\right)\end{array}$ & $\begin{array}{c}\text { Moisture } \\
\text { Ratio of Rice }\end{array}$ & $\begin{array}{c}\text { Total Drying } \\
\text { Accumulated } \\
\text { Temperature } \\
\left({ }^{\circ} \mathrm{C} \cdot \mathrm{h}\right)\end{array}$ \\
\hline 0 & 21.00 & 26.58 & -51.3148 & 0 & 1 & 0 \\
\hline 0.25 & 20.80 & 26.27 & -50.3255 & 9.0555 & 0.9747 & 9.0555 \\
\hline 0.5 & 20.45 & 25.71 & -49.4022 & 19.1005 & 0.9318 & 28.156 \\
\hline 0.75 & 20.09 & 25.14 & -48.3732 & 18.8433 & 0.8885 & 46.9993 \\
\hline 1 & 19.48 & 24.20 & -46.3953 & 36.6976 & 0.8161 & 83.697 \\
\hline 1.25 & 18.92 & 23.34 & -44.2782 & 35.6391 & 0.7502 & 119.3361 \\
\hline 1.5 & 18.39 & 22.54 & -42.0044 & 34.5022 & 0.6892 & 153.8383 \\
\hline 1.75 & 17.90 & 21.80 & -39.5787 & 33.2893 & 0.6325 & 187.1276 \\
\hline 2 & 17.42 & 21.09 & -36.9381 & 31.969 & 0.5784 & 219.0967 \\
\hline 2.25 & 17.00 & 20.49 & -34.3969 & 30.6984 & 0.532 & 249.7951 \\
\hline 2.5 & 16.64 & 19.96 & -31.9498 & 29.4749 & 0.4917 & 279.27 \\
\hline 2.75 & 16.24 & 19.39 & -28.9984 & 27.9992 & 0.4477 & 307.2692 \\
\hline 3 & 15.95 & 18.97 & -26.6788 & 26.8394 & 0.4161 & 334.1086 \\
\hline 3.25 & 15.65 & 18.55 & -24.1059 & 25.5529 & 0.3835 & 359.6615 \\
\hline 3.5 & 15.33 & 18.11 & -21.2302 & 24.1151 & 0.3499 & 383.7766 \\
\hline 3.75 & 15.05 & 17.72 & -18.4833 & 22.7417 & 0.32 & 406.5183 \\
\hline 4 & 14.80 & 17.37 & -15.8439 & 21.422 & 0.2932 & 427.9403 \\
\hline 4.25 & 14.54 & 17.02 & -13.0109 & 20.0055 & 0.2662 & 447.9458 \\
\hline 4.5 & 14.34 & 16.75 & -10.7278 & 18.8639 & 0.2456 & 466.8097 \\
\hline 4.75 & 14.16 & 16.49 & -8.4869 & 17.7434 & 0.2263 & 484.5531 \\
\hline 5 & 13.95 & 16.22 & -5.8789 & 16.4395 & 0.2049 & 500.9926 \\
\hline 5.25 & 13.77 & 15.97 & -3.518 & 15.259 & 0.1864 & 516.2515 \\
\hline 5.5 & 13.61 & 15.75 & -1.2572 & 14.1286 & 0.1694 & 530.3801 \\
\hline 5.75 & 13.40 & 15.48 & 1.6521 & 12.6739 & 0.1485 & 543.0541 \\
\hline
\end{tabular}

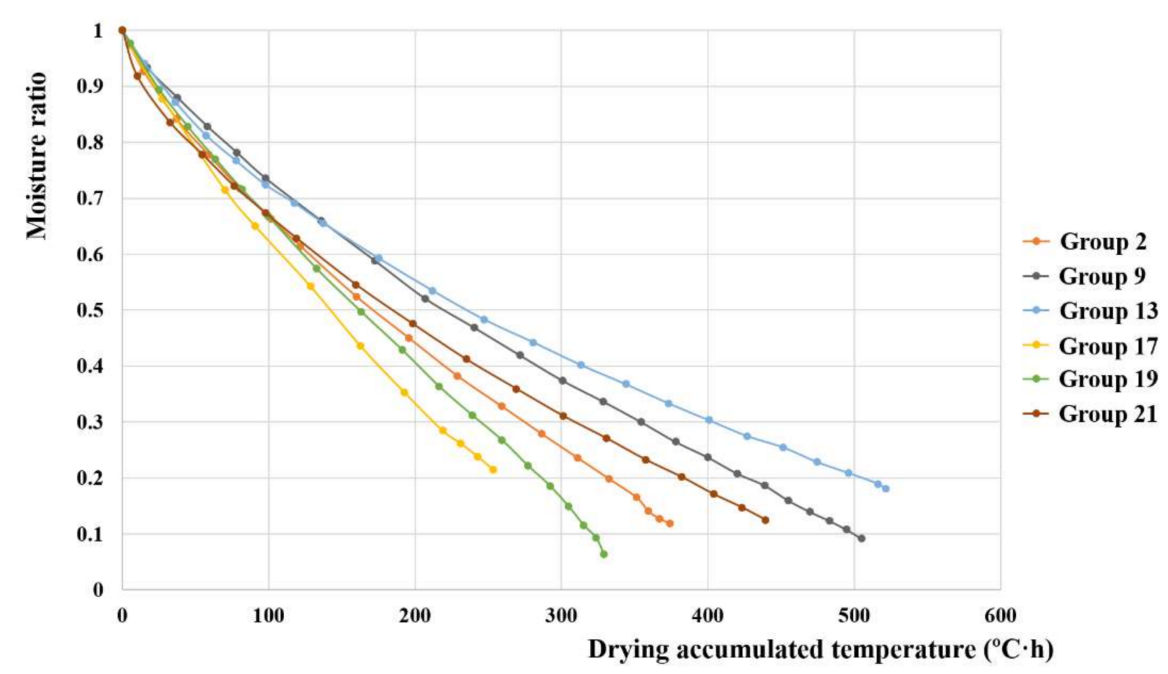

Figure 2. Drying accumulated temperature versus moisture ratio.

Multivariate quadratic regression analysis of the test results was carried out with Design-Expert V12.0 software. The following regression model relating the various factors to the drying accumulated temperature [23] was established:

$$
A T=-428.23-26.33 X_{1}+3.44 X_{2}+89.56 X_{3}-0.20 X_{2} X_{4}+0.25 X_{1}^{2}-1.82 X_{3}^{2},
$$

the $\mathrm{F}$ value of this model was 38.361. The $p$ values for the significant terms were less than 0.0001 , and the $R^{2}$ value was 0.9553 , indicating that the model was extremely significant.

\subsection{Model Selection Method}

Based on the concept of effective accumulated temperature and the existing mathematical drying models, a model relating the accumulated temperature and the moisture ratio of rice was constructed. MATLAB was used to carry out the fitting calculations on the test data 
and evaluate the fitting degree of the various models. The model with the best fitting degree was selected as the mathematical model of effective drying accumulated temperature.

Several exponential equations (Table 4) were selected as the drying accumulated temperature models in order to analyze the experimental drying data. The fitting accuracies of the experimental data to the thin-layer models were evaluated using the coefficient of determination $\left(R^{2}\right)$, chi squared $\left(\chi^{2}\right)$, and root mean square error (RMSE). $R^{2}$ is defined as follows:

$$
R^{2}=1-\frac{\sum_{i=1}^{n}\left(M R_{i, \mathrm{pre}}-M R_{i, \exp }\right)^{2}}{\sum_{i=1}^{n}\left(M R_{i, \exp }-\overline{M R_{\exp }}\right)^{2}},
$$

where $M R_{i, \exp }$ is the moisture ratio calculated based on the experimental data, $M R_{i \text {,pre }}$ is predicted by the thin layer model, and $\overline{M R_{\text {exp }}}$ is the mean of the actual moisture ratio of the experiment; $\chi^{2}$ and RMSE are defined as follows:

$$
\begin{aligned}
\chi^{2} & =\frac{\sum_{i=1}^{n}\left(M R_{i, \exp }-M R_{i, \mathrm{pre}}\right)^{2}}{N-Z}, \\
R M S E & =\sqrt{\frac{\sum_{i=1}^{n}\left(M R_{i, \mathrm{pre}}-M R_{i, \exp }\right)^{2}}{N} .} .
\end{aligned}
$$

Table 4. Several commonly used mathematical models.

\begin{tabular}{cccc}
\hline Model No. & Name & Model Equation & Modified Equation \\
\hline 1 & Linear equation & $M R=a t+b$ & $M R=a A T+b$ \\
2 & Polynomial equation & $M R=a t^{2}-b t+c$ & $M R=a A T^{2}-b A T+c$ \\
3 & Page & $M R=\exp \left(-k t^{n}\right)$ & $M R=\exp \left(-k A T^{n}\right)$ \\
4 & Modified Page II & $M R=a \exp \left(-k t^{n}\right)$ & $M R=a \exp \left(-k A T^{n}\right)$ \\
5 & Simplified modified Page II & $M R=a \exp \left(-t^{n}\right)$ & $M R=a \exp \left(-A T^{n}\right)$ \\
6 & Weibull II & $M R=\exp \left[-(t / \alpha)^{\beta}\right]$ & $M R=\exp \left[-(A T / a)^{b}\right]$ \\
7 & Midilli & $M R=a \exp \left(-k t^{n}\right)+b t$ & $M R=a \exp \left(-k A T^{n}\right)+b A T$ \\
\hline
\end{tabular}

\subsection{Drying Accumulated Temperature-Moisture Ratio Model}

In the previous study, 36 groups of experimental data were substituted into the seven mathematical models shown in Table 4, and the three indices described above were used to evaluate the models, as shown in Table 5. The Midilli model yielded an extremely significant fit to the test data, with an $R^{2}$ ranging from 0.998632 to 0.999964 . Hence, the Midilli model was selected to describe the relationship between the moisture ratio and drying accumulated temperature.

Table 5. Comparison of evaluation indicators.

\begin{tabular}{cccc}
\hline \multirow{2}{*}{ Model No. } & \multicolumn{3}{c}{ Range } \\
\cline { 2 - 4 } & $\boldsymbol{R}^{\mathbf{2}}$ & $\boldsymbol{\chi}^{\mathbf{2}} \mathbf{( 1 \mathbf { 1 0 } ^ { - \mathbf { 4 } } )}$ & $\boldsymbol{R} \boldsymbol{\text { MSE }} \mathbf{( 1 \mathbf { 1 0 } ^ { - 4 } \mathbf { ) }}$ \\
\hline 1 & $0.973769-0.999161$ & $0.5720432-19.53701$ & $0.0444922-17.26623$ \\
2 & $0.99196-0.999697$ & $0.0273277-7.422666$ & $0.218622-5.832094$ \\
3 & $0.984013-0.998321$ & $1.061333-14.11593$ & $0.928666-12.50415$ \\
4 & $0.986226-0.998438$ & $1.034447-12.90039$ & $0.840489-10.42148$ \\
5 & $0.17752-0.330753$ & $588.84853-879.66005$ & $510.48454-787.06426$ \\
6 & $0.984013-0.998321$ & $1.061333-14.11593$ & $0.928666-12.50415$ \\
7 & $0.998632-0.999964$ & $0.0301823-1.515054$ & $0.0226367-1.082181$ \\
\hline
\end{tabular}


Table 6 list the coefficients of the Midilli model for each group. The range of the constant $a$ was between 0.995622289 and 1.004246143 , which was very close to 1 . The ranges of $k$ and $b$ were from 0.002245885 to 0.048506864 and from -0.003868304 to -0.000344992 , respectively, which were very close to 0 . These values of $k$ and $b$ are not beneficial for further analysis of the regression models; $k$ and $b$ are too small because $A T$ is too large. Therefore, the Midilli model was redefined. The constant $a$ was set to 1 , and the value of $A T$ was scaled, yielding the following model:

$$
M R=\exp \left[-k(A T / 100)^{n}\right]+b(A T / 100) .
$$

Table 6. Coefficients of the Midilli drying accumulated temperature model.

\begin{tabular}{|c|c|c|c|c|}
\hline Group & $a$ & $k$ & $n$ & $\boldsymbol{b}$ \\
\hline 1 & 1.00101 & 0.035269 & 0.715627 & -0.00205125 \\
\hline 2 & 1.00139 & 0.00926442 & 0.692957 & -0.00102529 \\
\hline 3 & 0.999012 & 0.00427439 & 0.783375 & -0.00196273 \\
\hline 4 & 1.0009 & 0.00537334 & 0.530844 & -0.0038683 \\
\hline 5 & 0.999496 & 0.00650352 & 0.847199 & -0.000580394 \\
\hline 6 & 1.0001 & 0.00552916 & 0.835148 & -0.000493744 \\
\hline 7 & 1.00039 & 0.00456589 & 0.751331 & -0.00242506 \\
\hline 8 & 1.00139 & 0.00642331 & 0.68537 & -0.00204891 \\
\hline 9 & 1.00164 & 0.00645302 & 0.762578 & -0.000657588 \\
\hline 10 & 1.00057 & 0.00553006 & 0.788037 & -0.00074992 \\
\hline 11 & 1.00109 & 0.00316241 & 0.780761 & -0.00237464 \\
\hline 12 & 0.998202 & 0.00468692 & 0.766306 & -0.00130538 \\
\hline 13 & 1.00257 & 0.00607272 & 0.72201 & -0.000390238 \\
\hline 14 & 0.998687 & 0.00676858 & 0.83013 & -0.000344992 \\
\hline 15 & 1.00164 & 0.00517981 & 0.754991 & -0.000539943 \\
\hline 16 & 1.00153 & 0.0129326 & 0.757631 & -0.000539744 \\
\hline 17 & 0.999883 & 0.00441983 & 0.916641 & -0.000969152 \\
\hline 18 & 1.00005 & 0.00437859 & 0.854193 & -0.000567743 \\
\hline 19 & 1.00343 & 0.00921075 & 0.742537 & -0.00208353 \\
\hline 20 & 1.0017 & 0.00531923 & 0.688852 & -0.000702075 \\
\hline 21 & 0.99793 & 0.0120082 & 0.640903 & -0.000764778 \\
\hline 22 & 0.999311 & 0.00673804 & 0.704464 & -0.00312659 \\
\hline 23 & 1.0017 & 0.006308 & 0.732581 & -0.000777213 \\
\hline 24 & 1.00244 & 0.00926204 & 0.750457 & -0.00132015 \\
\hline 25 & 1.00168 & 0.00542829 & 0.842068 & -0.000875988 \\
\hline 26 & 1.00078 & 0.00575557 & 0.835284 & -0.000762651 \\
\hline 27 & 1.00142 & 0.00563226 & 0.835448 & -0.0018802 \\
\hline 28 & 1.00033 & 0.00944224 & 0.731882 & -0.00109802 \\
\hline 29 & 1.001 & 0.00533085 & 0.849266 & -0.000780637 \\
\hline 30 & 1.00249 & 0.00559346 & 0.831682 & -0.00102325 \\
\hline 31 & 1.00158 & 0.00530231 & 0.843352 & -0.00199305 \\
\hline 32 & 1.00199 & 0.0100175 & 0.700704 & -0.00158544 \\
\hline 33 & 1.00002 & 0.00524587 & 0.864654 & -0.000709403 \\
\hline 34 & 1.00075 & 0.00574093 & 0.847738 & -0.00067994 \\
\hline 35 & 1.00024 & 0.00585991 & 0.831015 & -0.000714326 \\
\hline 36 & 1.00081 & 0.0147862 & 0.673304 & -0.00126142 \\
\hline
\end{tabular}

The reconstructed model was used to fit the test data in order to obtain new evaluation parameter values for each experimental model. The ranges of these parameters were as follows: $R^{2}=0.998615-0.999964, \chi^{2}=0.0280372-1.408121$, and $R M S E=0.0227802-1.106381$. Thus, the new model had high accuracy and achieved good predictive performance. Finally, this model was selected as the mathematical model of the relationship between the moisture ratio and drying accumulated temperature of rice. We have named this model the accumulative temperature-moisture ratio model, or AT-MR Model. 


\subsection{Regression Equations of AT-MR Model Parameters}

The values of $k, n$, and $b$ in the AT-MR model for each group are listed in Table 7. Based on the values of the control factors for each experimental group and corresponding coefficients of AT-MR model, a multivariate quadratic analysis was conducted using the Design-Expert V12.0 software in order to determine the dependence of the coefficients on the control factors.

Table 7. Coefficients of AT-MR model.

\begin{tabular}{|c|c|c|c|}
\hline Group & $k$ & $n$ & $b$ \\
\hline 1 & 0.0306137 & 0.722394 & -0.00205125 \\
\hline 2 & 0.00573271 & 0.707736 & -0.00102529 \\
\hline 3 & 0.00252274 & 0.775986 & -0.00196273 \\
\hline 4 & 0.00485107 & 0.538049 & -0.0038683 \\
\hline 5 & 0.00527444 & 0.83999 & -0.000580394 \\
\hline 6 & 0.00590817 & 0.838778 & -0.000493744 \\
\hline 7 & 0.00596193 & 0.754152 & -0.00242506 \\
\hline 8 & 0.00977103 & 0.700251 & -0.00204891 \\
\hline 9 & 0.00340685 & 0.778977 & -0.000657588 \\
\hline 10 & 0.00385712 & 0.790293 & -0.00074992 \\
\hline 11 & 0.0023295 & 0.790945 & -0.00237464 \\
\hline 12 & 0.00600094 & 0.758982 & -0.00130538 \\
\hline 13 & 0.0057322 & 0.729039 & -0.000390238 \\
\hline 14 & 0.00875264 & 0.822986 & -0.000344992 \\
\hline 15 & 0.00744517 & 0.771492 & -0.000539943 \\
\hline 16 & 0.0173073 & 0.764295 & -0.000539744 \\
\hline 17 & 0.00281839 & 0.913017 & -0.000969152 \\
\hline 18 & 0.00608254 & 0.849176 & -0.000567743 \\
\hline 19 & 0.00536611 & 0.760183 & -0.00208353 \\
\hline 20 & 0.00762352 & 0.704859 & -0.000702075 \\
\hline 21 & 0.00937648 & 0.641548 & -0.000764778 \\
\hline 22 & 0.0102441 & 0.70608 & -0.00312659 \\
\hline 23 & 0.00463416 & 0.741747 & -0.000777213 \\
\hline 24 & 0.00982486 & 0.761552 & -0.00132015 \\
\hline 25 & 0.00522365 & 0.851915 & -0.000875988 \\
\hline 26 & 0.00560364 & 0.84138 & -0.000762651 \\
\hline 27 & 0.00544327 & 0.843705 & -0.0018802 \\
\hline 28 & 0.00928736 & 0.736501 & -0.00109802 \\
\hline 29 & 0.00517718 & 0.855992 & -0.000780637 \\
\hline 30 & 0.00534153 & 0.843632 & -0.00102325 \\
\hline 31 & 0.00510717 & 0.853163 & -0.00199305 \\
\hline 32 & 0.00950335 & 0.711821 & -0.00158544 \\
\hline 33 & 0.00514296 & 0.868341 & -0.000709403 \\
\hline 34 & 0.0055955 & 0.85349 & -0.00067994 \\
\hline 35 & 0.00574205 & 0.83538 & -0.000714326 \\
\hline 36 & 0.014516 & 0.678433 & -0.00126142 \\
\hline
\end{tabular}

After regression analysis and eliminating terms that had no significant influence, the regression models for $k, n$, and $b$ were given, respectively, as follows:

$$
\begin{aligned}
& k=0.39569-0.073959 X_{1}+0.035775 X_{2}+0.051727 X_{3}-2.26567 X_{4} \\
& +0.00276245 X_{1} X_{3}+0.033933 X_{1} X_{4}+0.027286 X_{2} X_{4}-0.016476 X_{3} X_{4} \\
& -0.0005177 X_{2}^{2}-0.00258296 X_{3}^{2} \\
& n=-8.29598-0.035018 X_{1}+0.14793 X_{2}+0.51264 X_{3}+2.88286 X_{4} \\
& -0.00107225 X_{1} X_{2}+0.002423 X_{1} X_{3}+0.058408 X_{1} X_{4}+0.037446 X_{2} X_{4} \\
& -0.15552 X_{3} X_{4}-0.00134958 X_{2}^{2}-0.012104 X_{3}^{2}-2.89574 X_{4}^{2} \\
& b=-2.3146-0.070883 X_{1}+0.048904 X_{2}+0.20896 X_{3}+0.011486 X_{4} \\
& +0.00294823 X_{1} X_{3}-0.000517492 X_{2}^{2}-0.00676184 X_{3}^{2}
\end{aligned}
$$

and the corresponding $R^{2}$ values were $0.9225,0.9553$, and 0.9131 . 


\section{Materials and Methods}

\subsection{Equipment and Method}

In this study, a new experimental scheme was designed which included the tempering ratio in the control factor based on the previous experiment, and appropriately expanded the level range. The level coding table of each factor in this experiment is shown in Table 8. The calculation formula of the tempering ratio is as follows:

$$
T R=\frac{t_{T}}{t_{D}}
$$

where $T R$ is the tempering ratio, $t_{T}$ is the tempering time $(\mathrm{h}), t_{D}$ is the drying time $(\mathrm{h})$.

Table 8. Experimental factors and their levels.

\begin{tabular}{cccccc}
\hline Factor & \multicolumn{5}{c}{ Level } \\
\cline { 2 - 6 } & $\mathbf{- 2}$ & $\mathbf{- 1}$ & $\mathbf{0}$ & $\mathbf{1}$ & $\mathbf{2}$ \\
\hline Hot air temperature $\mathrm{X}_{1} /{ }^{\circ} \mathrm{C}$ & 32.99 & 38.5 & 42.5 & 46.5 & 52.01 \\
Relative humidity of hot air $\mathrm{X}_{2} / \%$ & 41.11 & 48 & 53 & 58 & 64.89 \\
Initial moisture content of rice $\mathrm{X}_{3} / \%$ & 16.03 & 19.2 & 21.5 & 23.8 & 26.97 \\
Velocity of hot air $\mathrm{X}_{4} / \mathrm{m} \mathrm{s}^{-1}$ & 0.36 & 0.5 & 0.6 & 0.7 & 0.84 \\
Tempering ratio $\mathrm{X}_{5}$ & 0 & 1.45 & 2.5 & 3.55 & 5 \\
\hline
\end{tabular}

The experiment was started in October 2020, with a total of 59 groups of experiments lasting 30 days. To avoid any influence on the test results from rice variety, only "Huang Hua Zhan" (a particular type of high-quality, late indica rice from China) was selected for this experiment. A multi-parameter controllable drying apparatus was used for the tests, as shown in Figure 3. The main function of this equipment was to accurately control the drying environment of the materials. The control accuracies were as follows: hot air temperature $\pm 0.5^{\circ} \mathrm{C}$, hot air relative humidity $\pm 1 \%$, and velocity of hot air $\pm 0.1 \mathrm{~m} \mathrm{~s}^{-1}$. Samples with different initial moisture contents were prepared prior to the start of the test. First, $1000 \mathrm{~g}$ of a test sample was inserted into a material sieve. The stainless-steel material sieve with a 12-mesh screen at the bottom was used to hold the rice grains while allowing hot air to pass through the grain layer. The samples were then inserted into the test chamber, the chamber door was closed, the time was recorded, and the test was started.
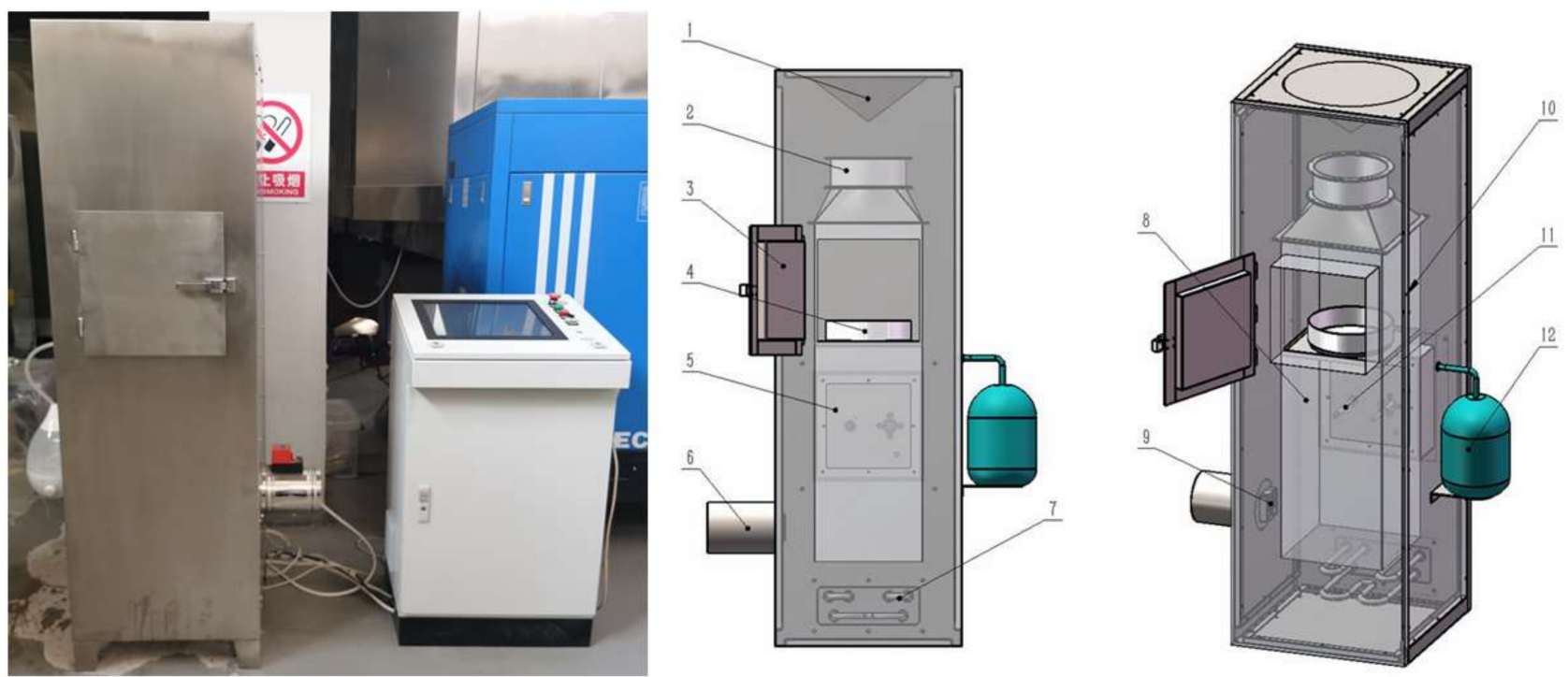

Figure 3. Multi-parameter-controllable drying test device: 1. wind shunt, 2. axial flow fan, 3. material bin door, 4 . material sieve, 5. sensor bin, 6. electric sealing valve, 7. heating pipe, 8. inner tank, 9. wet exhaust fan, 10. test-bed shell, 11. sensor group, and 12. humidifier. 
In this experiment, the real-time moisture content in the drying process was determined by a weighing method. After the start of the test, the material sieve was removed and weighed every $15 \mathrm{~min}$, and the time and weight were recorded and input into the computer. The formula for calculating the moisture $\left(M_{t}\right)$ for the weighing method was as follows:

$$
M_{t}=\frac{m_{s t}}{m_{t}}=\frac{M_{0} * m_{o}-\left(m_{0}-m_{t}\right)}{m_{t}}=1-\frac{m_{0}}{m_{t}}\left(1-M_{0}\right),
$$

where $m_{s t}$ is the moisture mass of the rice sample at time $t(\mathrm{~g}), m_{t}$ is the net weight of the rice sample at time $t(\mathrm{~g}), m_{0}$ is the initial mass of the rice sample $(\mathrm{g})$, and $M_{0}$ is the initial moisture content (wet basis) of the rice sample (\%). The drying test ended when the moisture content of the rice sample decreased to about $13.5 \%$ (wet basis).

\subsection{The Test Results}

The test results were as shown in Table 9.

According to the method in 3.2, the MATLAB program was used to process the test data, and the seven models in Table 4 along with the AT-MR model were used to fit the data.

From the comparison of model accuracy (Table 10), the best two fitting effects were the imitation Midilli equation (model 7) and AT-MR model (model 8), both of which models were extremely significant. The simplified modified Page II equation (model 5) had the worst fitting effect, with an $R^{2}$ range of only $0.164896-0.378380$. Therefore, the AT-MR model was selected as the rice drying accumulated temperature model with tempering process.

\subsection{Analysis of the Effect of the Tempering Process on Rice Drying}

In order to explore the influence of the tempering process on rice drying, the tempering time was ignored in the analysis of experimental data in this section, while the influence of tempering on the drying results was retained. When the time of the two models only includes the pure drying time, the influence of the tempering process on the whole drying operation can be directly reflected by comparing the coefficients and the moisture content of the two models. The essence of this approach is to explain the physical phenomena in the process of rice drying from a mathematical perspective. The specific approach was as follows: the tempering time in this test was removed; thus, only the drying time was left. Then, the AT-MR model was used to fit the data, and the new model was named "control group model". The three coefficients, $k, n$ and $b$, of the control group model were extracted (Table 11), and the regression model of the three coefficients was established.

After regression analysis and eliminating terms that had no significant influence, the regression models for $k, n$, and $b$ of the control group model were given, respectively, as follows:

$$
\begin{aligned}
k= & \left(1326.42+17.022 X_{1}+90.219 X_{2}-345.65 X_{3}+63.734 X_{4}+54.171 X_{5}\right. \\
& \left.+39.794 X_{2} X_{4}-1.15413 X_{2}^{2}+7.39963 X_{3}^{2}-1430.72 X_{4}^{2}\right) \times 10^{-3} \\
n= & \left(-14569.6+177.54 X_{1}+239.71 X_{2}+314.46 X_{3}+6536.31 X_{4}+229.01 X_{5}\right. \\
& -2.53375 X_{1} X_{3}-6.58083 X_{1} X_{5}-4.26485 X_{2} X_{3}-75.752 X_{2} X_{4} \\
& +7.89437 X_{2} X_{5}-101.26 X_{3} X_{4}-14.194 X_{3} X_{5}-215.72 X_{4} X_{5} \\
& \left.-1.21559 X_{1}^{2}-1.15002 X_{2}^{2}+2.10684 X_{3}^{2}+25.335 X_{5}^{2}\right) \times 10^{-3} \\
b= & \left(-2156.4+382.09 X_{1}+438.35 X_{2}-1339.4 X_{3}-13037.1 X_{4}+1588.5 X_{5}\right. \\
& -5.71409 X_{1} X_{3}-21.4225 X_{1} X_{5}+8.35782 X_{2} X_{3}-34.1126 X_{3} X_{5} \\
& -869.64 X_{4} X_{5}-2.72111 X_{1}^{2}-6.41402 X_{2}^{2}+28.5646 X_{3}^{2} \\
& \left.+12454.8 X_{4}^{2}+121.98 X_{5}^{2}\right) \times 10^{-4}
\end{aligned}
$$

and the corresponding $R^{2}$ values were $0.9113,0.9415$, and 0.9314 . 
Table 9. The test results.

\begin{tabular}{|c|c|c|c|c|c|c|}
\hline Group & $\begin{array}{c}X_{1} \\
\left({ }^{\circ} \mathrm{C}\right)\end{array}$ & $\begin{array}{l}X_{2} \\
(\%)\end{array}$ & $\begin{array}{c}X_{3} \\
\text { (\%w.b.) }\end{array}$ & $\begin{array}{c}X_{4} \\
(\mathrm{~m} / \mathrm{s})\end{array}$ & $X_{5}$ & $\begin{array}{l}\text { Drying Accumulated Temperature } \\
\qquad\left({ }^{\circ} \mathrm{C} \cdot \mathrm{h}\right)\end{array}$ \\
\hline 1 & 38.5 & 48 & 19.2 & 0.5 & 1.45 & 412.53 \\
\hline 2 & 46.5 & 48 & 19.2 & 0.5 & 1.45 & 345.73 \\
\hline 3 & 38.5 & 58 & 19.2 & 0.5 & 1.45 & 525.72 \\
\hline 4 & 46.5 & 58 & 19.2 & 0.5 & 1.45 & 369.68 \\
\hline 5 & 38.5 & 48 & 23.8 & 0.5 & 1.45 & 659.89 \\
\hline 6 & 46.5 & 48 & 23.8 & 0.5 & 1.45 & 466.16 \\
\hline 7 & 38.5 & 58 & 23.8 & 0.5 & 1.45 & 825.44 \\
\hline 8 & 46.5 & 58 & 23.8 & 0.5 & 1.45 & 592.29 \\
\hline 9 & 38.5 & 48 & 19.2 & 0.7 & 1.45 & 368.45 \\
\hline 10 & 46.5 & 48 & 19.2 & 0.7 & 1.45 & 377.58 \\
\hline 11 & 38.5 & 58 & 19.2 & 0.7 & 1.45 & 493.96 \\
\hline 12 & 46.5 & 58 & 19.2 & 0.7 & 1.45 & 354.42 \\
\hline 13 & 38.5 & 48 & 23.8 & 0.7 & 1.45 & 522.83 \\
\hline 14 & 46.5 & 48 & 23.8 & 0.7 & 1.45 & 385.02 \\
\hline 15 & 38.5 & 58 & 23.8 & 0.7 & 1.45 & 698.01 \\
\hline 16 & 46.5 & 58 & 23.8 & 0.7 & 1.45 & 446.63 \\
\hline 17 & 38.5 & 48 & 19.2 & 0.5 & 3.55 & 600.22 \\
\hline 18 & 46.5 & 48 & 19.2 & 0.5 & 3.55 & 435.47 \\
\hline 19 & 38.5 & 58 & 19.2 & 0.5 & 3.55 & 892.62 \\
\hline 20 & 46.5 & 58 & 19.2 & 0.5 & 3.55 & 628.91 \\
\hline 21 & 38.5 & 48 & 23.8 & 0.5 & 3.55 & 919.96 \\
\hline 22 & 46.5 & 48 & 23.8 & 0.5 & 3.55 & 674.48 \\
\hline 23 & 38.5 & 58 & 23.8 & 0.5 & 3.55 & 1388.81 \\
\hline 24 & 46.5 & 58 & 23.8 & 0.5 & 3.55 & 956.27 \\
\hline 25 & 38.5 & 48 & 19.2 & 0.7 & 3.55 & 544.39 \\
\hline 26 & 46.5 & 48 & 19.2 & 0.7 & 3.55 & 383.39 \\
\hline 27 & 38.5 & 58 & 19.2 & 0.7 & 3.55 & 775.43 \\
\hline 28 & 46.5 & 58 & 19.2 & 0.7 & 3.55 & 485.93 \\
\hline 29 & 38.5 & 48 & 23.8 & 0.7 & 3.55 & 812.97 \\
\hline 30 & 46.5 & 48 & 23.8 & 0.7 & 3.55 & 475.65 \\
\hline 31 & 38.5 & 58 & 23.8 & 0.7 & 3.55 & 1051.05 \\
\hline 32 & 46.5 & 58 & 23.8 & 0.7 & 3.55 & 694.71 \\
\hline 33 & 32.99 & 53 & 21.5 & 0.6 & 2.5 & 806.94 \\
\hline 34 & 52.01 & 53 & 21.5 & 0.6 & 2.5 & 396.84 \\
\hline 35 & 42.5 & 41.11 & 21.5 & 0.6 & 2.5 & 442.64 \\
\hline 36 & 42.5 & 64.89 & 21.5 & 0.6 & 2.5 & 845.54 \\
\hline 37 & 42.5 & 53 & 16.03 & 0.6 & 2.5 & 216.11 \\
\hline 38 & 42.5 & 53 & 26.97 & 0.6 & 2.5 & 726.54 \\
\hline 39 & 42.5 & 53 & 21.5 & 0.36 & 2.5 & 1133.86 \\
\hline 40 & 42.5 & 53 & 21.5 & 0.84 & 2.5 & 680.00 \\
\hline 41 & 42.5 & 53 & 21.5 & 0.6 & 2.5 & 272.64 \\
\hline 42 & 42.5 & 53 & 21.5 & 0.6 & 5 & 788.59 \\
\hline 43 & 42.5 & 53 & 21.5 & 0.6 & 2.5 & 595.00 \\
\hline 44 & 42.5 & 53 & 21.5 & 0.6 & 2.5 & 529.55 \\
\hline 45 & 42.5 & 53 & 21.5 & 0.6 & 2.5 & 488.75 \\
\hline 46 & 42.5 & 53 & 21.5 & 0.6 & 2.5 & 546.98 \\
\hline 47 & 42.5 & 53 & 21.5 & 0.6 & 2.5 & 603.50 \\
\hline 48 & 42.5 & 53 & 21.5 & 0.6 & 2.5 & 567.38 \\
\hline 49 & 42.5 & 53 & 21.5 & 0.6 & 2.5 & 573.75 \\
\hline 50 & 42.5 & 53 & 21.5 & 0.6 & 2.5 & 579.70 \\
\hline 51 & 42.5 & 53 & 21.5 & 0.6 & 2.5 & 529.55 \\
\hline 52 & 42.5 & 53 & 21.5 & 0.6 & 2.5 & 494.91 \\
\hline 53 & 42.5 & 53 & 21.5 & 0.6 & 2.5 & 546.98 \\
\hline 54 & 42.5 & 53 & 21.5 & 0.6 & 2.5 & 480.25 \\
\hline 55 & 42.5 & 53 & 21.5 & 0.6 & 2.5 & 567.38 \\
\hline 56 & 42.5 & 53 & 21.5 & 0.6 & 2.5 & 573.75 \\
\hline 57 & 42.5 & 53 & 21.5 & 0.6 & 2.5 & 529.55 \\
\hline 58 & 42.5 & 53 & 21.5 & 0.6 & 2.5 & 494.91 \\
\hline 59 & 42.5 & 53 & 21.5 & 0.6 & 2.5 & 546.98 \\
\hline
\end{tabular}


Table 10. Comparison of evaluation indicators.

\begin{tabular}{cccc}
\hline \multirow{2}{*}{ Model No. } & \multicolumn{3}{c}{ Range } \\
\cline { 2 - 4 } & $\boldsymbol{R}^{\mathbf{2}}$ & $\boldsymbol{\chi}^{\mathbf{2}} \mathbf{( 1 \mathbf { 1 0 } ^ { - 4 } \mathbf { ) }}$ & $\boldsymbol{R} \boldsymbol{\text { MSE }} \mathbf{( \mathbf { 1 0 }} \mathbf{- 4}^{\mathbf{4}}$ \\
\hline 1 & $0.924177-0.997569$ & $2.3567-53.088$ & $2.0425-51.157$ \\
2 & $0.996039-0.999912$ & $0.061578-2.9869$ & $0.049262-2.7069$ \\
3 & $0.982072-0.999526$ & $0.32871-17.409$ & $0.29740-16.017$ \\
4 & $0.985405-0.999576$ & $0.26662-14.172$ & $0.22853-12.472$ \\
5 & $0.164896-0.378380$ & $474.41-985.24$ & $435.69-821.04$ \\
6 & $0.982072-0.999526$ & $0.32871-17.409$ & $0.29740-16.017$ \\
7 & $0.997647-0.999979$ & $0.016892-2.0295$ & $0.014076-1.6023$ \\
8 & $0.997548-0.999979$ & $0.016273-2.0163$ & $0.014239-1.6979$ \\
\hline
\end{tabular}

Table 11. Coefficients of the control group model.

\begin{tabular}{|c|c|c|c|}
\hline Group & $k$ & $n$ & $b$ \\
\hline 1 & 0.341389 & 0.834138 & -0.0489694 \\
\hline 2 & 0.468729 & 0.978014 & -0.0377525 \\
\hline 3 & 0.278803 & 0.907038 & -0.114835 \\
\hline 4 & 0.396636 & 1.03552 & -0.107336 \\
\hline 5 & 0.270643 & 0.952394 & -0.0309789 \\
\hline 6 & 0.346402 & 0.983138 & -0.0416091 \\
\hline 7 & 0.235325 & 0.901302 & -0.0569887 \\
\hline 8 & 0.29801 & 0.938925 & -0.0709415 \\
\hline 9 & 0.384782 & 0.96074 & -0.0261712 \\
\hline 10 & 0.519735 & 1.07809 & -0.0129317 \\
\hline 11 & 0.329509 & 0.92236 & -0.0956808 \\
\hline 12 & 0.45681 & 1.0106 & -0.0969446 \\
\hline 13 & 0.305711 & 0.973768 & -0.0319343 \\
\hline 14 & 0.434421 & 1.03235 & -0.0327374 \\
\hline 15 & 0.342004 & 0.781038 & -0.060188 \\
\hline 16 & 0.445894 & 0.788397 & -0.0730112 \\
\hline 17 & 0.43605 & 1.00398 & -0.0145096 \\
\hline 18 & 0.666164 & 1.07885 & -0.00814848 \\
\hline 19 & 0.32739 & 1.3173 & -0.0545716 \\
\hline 20 & 0.401572 & 1.3462 & -0.0950719 \\
\hline 21 & 0.352323 & 1.02753 & -0.0207138 \\
\hline 22 & 0.430171 & 0.986659 & -0.0531129 \\
\hline 23 & 0.255964 & 1.1299 & -0.0270968 \\
\hline 24 & 0.319665 & 1.03021 & -0.0801716 \\
\hline 25 & 0.4565 & 1.07825 & -0.0225678 \\
\hline 26 & 0.57383 & 1.03232 & -0.0551755 \\
\hline 27 & 0.404316 & 1.21928 & -0.0633263 \\
\hline 28 & 0.550427 & 1.22649 & -0.082667 \\
\hline 29 & 0.338439 & 1.02329 & -0.0380423 \\
\hline 30 & 0.568301 & 0.926364 & -0.0633409 \\
\hline 31 & 0.353745 & 0.903214 & -0.0706163 \\
\hline 32 & 0.478514 & 0.803443 & -0.111609 \\
\hline 33 & 0.319031 & 0.842192 & -0.0744975 \\
\hline 34 & 0.469749 & 0.938362 & -0.120622 \\
\hline 35 & 0.368043 & 0.885021 & -0.077033 \\
\hline 36 & 0.174089 & 0.790303 & -0.223813 \\
\hline 37 & 0.709576 & 1.19667 & -0.000305122 \\
\hline 38 & 0.417963 & 0.930018 & -0.0186425 \\
\hline 39 & 0.221123 & 1.02904 & -0.0177394 \\
\hline 40 & 0.445099 & 0.964506 & -0.0252461 \\
\hline 41 & 0.262261 & 1.01861 & -0.0255577 \\
\hline 42 & 0.538269 & 1.298 & -0.00843418 \\
\hline 43 & 0.454673 & 1.00279 & -0.0629393 \\
\hline
\end{tabular}


Table 11. Cont.

\begin{tabular}{cccc}
\hline Group & $\boldsymbol{k}$ & $\boldsymbol{n}$ & $\boldsymbol{b}$ \\
\hline 44 & 0.353997 & 0.95054 & -0.0830329 \\
45 & 0.439489 & 0.961908 & -0.0700671 \\
46 & 0.423663 & 0.986718 & -0.0666787 \\
47 & 0.412275 & 0.998257 & -0.0691629 \\
48 & 0.393799 & 0.983384 & -0.0698121 \\
49 & 0.385122 & 1.05931 & -0.0523508 \\
50 & 0.38372 & 1.05168 & -0.0651892 \\
51 & 0.408308 & 0.985089 & -0.0797404 \\
52 & 0.370361 & 0.981359 & -0.0730344 \\
53 & 0.391368 & 0.952122 & -0.0632013 \\
54 & 0.439184 & 1.03834 & -0.0760649 \\
55 & 0.427071 & 1.02673 & -0.0601507 \\
56 & 0.385143 & 0.967961 & -0.0673409 \\
57 & 0.414075 & 0.987404 & -0.059813 \\
58 & 0.451924 & 0.967198 & -0.0665639 \\
59 & 0.413357 & 1.03205 & -0.0790877 \\
\hline
\end{tabular}

In order to create a comparable condition, the intersection of the two tests was taken to determine the level of each factor, as shown in Table 12, and a factor combination scheme table was established, as shown in Table 13. Among these, the hot air temperature was fixed at $39^{\circ} \mathrm{C}$, which was set for three reasons: first, in actual drying operations, $39^{\circ} \mathrm{C}$ is the most common grain temperature in the rice drying process; second, the fluctuation range of grain temperature is not large in actual drying operations; and third, in the intersection set of the two tests, $39^{\circ} \mathrm{C}$ was the midpoint of the intersection, and the error of the calculation results was minimal, which meant that the comparison results had the highest reliability. In Table $13, X_{5}$ represents the tempering ratio. In this experiment, the three tempering ratios were set to be 1.5, 3 and 4.5. The tempering ratio of conventional rice dryers is usually fixed. Therefore, the tempering ratios were not involved in the permutation and combination of groups, but were substituted into each group of equations for calculation.

Table 12. Factors and their levels.

\begin{tabular}{cccccc}
\hline Level & $\begin{array}{c}\boldsymbol{X}_{\mathbf{1}} \\
\left({ }^{\circ} \mathbf{C}\right)\end{array}$ & $\begin{array}{c}\boldsymbol{X}_{\mathbf{2}} \\
\mathbf{( \% )}\end{array}$ & $\begin{array}{c}\boldsymbol{X}_{\mathbf{3}} \\
(\mathbf{\%}) \mathbf{w} . \mathbf{b} .)\end{array}$ & $\begin{array}{c}\boldsymbol{X}_{\mathbf{4}} \\
(\mathbf{m} / \mathbf{s})\end{array}$ & $\boldsymbol{X}_{\mathbf{5}}$ \\
\hline-1 & & 50 & 19 & 0.5 & 1.5 \\
0 & 39 & 54 & 21 & 0.6 & 3 \\
1 & & 58 & 23 & 0.7 & 4.5 \\
\hline
\end{tabular}

Table 13. Factor combination scheme.

\begin{tabular}{cccccc}
\hline Group & $\begin{array}{c}\boldsymbol{X}_{\mathbf{1}} \\
\left({ }^{\circ} \mathbf{C}\right)\end{array}$ & $\begin{array}{c}\boldsymbol{X}_{\mathbf{2}} \\
\mathbf{( \% )}\end{array}$ & $\begin{array}{c}\boldsymbol{X}_{\mathbf{3}} \\
(\mathbf{\%} \mathbf{w} \mathbf{c} \mathbf{)}\end{array}$ & $\begin{array}{c}\boldsymbol{X}_{\mathbf{4}} \\
(\mathbf{m} / \mathbf{s})\end{array}$ & $\boldsymbol{X}_{\mathbf{5}}$ \\
\hline 1 & 39 & 50 & 19 & 0.5 & $1.5 / 3 / 4.5$ \\
2 & 39 & 50 & 19 & 0.6 & $1.5 / 3 / 4.5$ \\
3 & 39 & 50 & 19 & 0.7 & $1.5 / 3 / 4.5$ \\
4 & 39 & 50 & 21 & 0.5 & $1.5 / 3 / 4.5$ \\
5 & 39 & 50 & 21 & 0.6 & $1.5 / 3 / 4.5$ \\
6 & 39 & 50 & 21 & 0.7 & $1.5 / 3 / 4.5$ \\
7 & 39 & 50 & 23 & 0.5 & $1.5 / 3 / 4.5$ \\
8 & 39 & 50 & 23 & 0.6 & $1.5 / 3 / 4.5$ \\
9 & 39 & 50 & 23 & 0.7 & $1.5 / 3 / 4.5$ \\
10 & 39 & 54 & 19 & 0.5 & $1.5 / 3 / 4.5$ \\
11 & 39 & 54 & 19 & 0.6 & $1.5 / 3 / 4.5$ \\
12 & 39 & 54 & 19 & 0.7 & $1.5 / 3 / 4.5$ \\
13 & 39 & 54 & 21 & 0.5 & $1.5 / 3 / 4.5$ \\
\hline
\end{tabular}


Table 13. Cont.

\begin{tabular}{cccccc}
\hline Group & $\begin{array}{c}\boldsymbol{X}_{\mathbf{1}} \\
\left({ }^{\circ} \mathbf{C}\right)\end{array}$ & $\begin{array}{c}\boldsymbol{X}_{\mathbf{2}} \\
\mathbf{( \% )}\end{array}$ & $\begin{array}{c}\boldsymbol{X}_{\mathbf{3}} \\
(\mathbf{\%} \mathbf{w} \mathbf{w} . \mathbf{)}\end{array}$ & $\begin{array}{c}\boldsymbol{X}_{\mathbf{4}} \\
(\mathbf{m} / \mathbf{s})\end{array}$ & $\boldsymbol{X}_{\mathbf{5}}$ \\
\hline 14 & 39 & 54 & 21 & 0.6 & $1.5 / 3 / 4.5$ \\
15 & 39 & 54 & 21 & 0.7 & $1.5 / 3 / 4.5$ \\
16 & 39 & 54 & 23 & 0.5 & $1.5 / 3 / 4.5$ \\
17 & 39 & 54 & 23 & 0.6 & $1.5 / 3 / 4.5$ \\
18 & 39 & 54 & 23 & 0.7 & $1.5 / 3 / 4.5$ \\
19 & 39 & 58 & 19 & 0.5 & $1.5 / 3 / 4.5$ \\
20 & 39 & 58 & 19 & 0.6 & $1.5 / 3 / 4.5$ \\
21 & 39 & 58 & 19 & 0.7 & $1.5 / 3 / 4.5$ \\
22 & 39 & 58 & 21 & 0.5 & $1.5 / 3 / 4.5$ \\
23 & 39 & 58 & 21 & 0.6 & $1.5 / 3 / 4.5$ \\
24 & 39 & 58 & 21 & 0.7 & $1.5 / 3 / 4.5$ \\
25 & 39 & 58 & 23 & 0.5 & $1.5 / 3 / 4.5$ \\
26 & 39 & 58 & 23 & 0.6 & $1.5 / 3 / 4.5$ \\
27 & 39 & 58 & 23 & 0.7 & $1.5 / 3 / 4.5$ \\
\hline
\end{tabular}

\section{Results}

First, the influencing factors in Table 13 were substituted into the model coefficient regression Equations (15)-(17) of the effective drying temperature without tempering as well as the model coefficient regression Equations (19)-(21) of the control group. Then, the coefficients of the two models were substituted into the effective drying accumulated temperature model, and the moisture ratio of the two models was calculated when the drying accumulated temperature was $200{ }^{\circ} \mathrm{C} \cdot \mathrm{h}$. Finally, the corresponding dry basis moisture was calculated by moisture ratio; some calculation results are shown in Table 14.

Table 14. Coefficient and moisture calculation results of the model.

\begin{tabular}{ccccccccc}
\hline \multirow{2}{*}{ Group } & \multicolumn{3}{c}{ Tempering Ratio $=\mathbf{3}$} & \multicolumn{4}{c}{ Non-Tempering } \\
\cline { 2 - 9 } & $\boldsymbol{k}$ & $\boldsymbol{n}$ & $\boldsymbol{b}$ & $\boldsymbol{M} \mathbf{( \% )}$ & $\boldsymbol{k}$ & $\boldsymbol{n}$ & $\boldsymbol{b}$ & $\boldsymbol{M} \mathbf{( \% )}$ \\
\hline 1 & 0.55137 & 1.03118 & -0.0239 & 13.928 & 0.15751 & 0.75148 & -0.2079 & 14.453 \\
2 & 0.59933 & 1.04894 & -0.0433 & 13.413 & 0.16840 & 0.84077 & -0.2068 & 14.277 \\
3 & 0.61868 & 1.06670 & -0.0379 & 13.379 & 0.17930 & 0.87214 & -0.2056 & 14.157 \\
4 & 0.45204 & 1.01811 & -0.0447 & 14.793 & 0.25332 & 0.84195 & -0.1010 & 15.892 \\
5 & 0.50000 & 1.01562 & -0.0641 & 14.114 & 0.26092 & 0.90013 & -0.0998 & 15.728 \\
6 & 0.51935 & 1.01312 & -0.0587 & 14.092 & 0.26852 & 0.90040 & -0.0987 & 15.670 \\
7 & 0.41191 & 1.02189 & -0.0427 & 15.822 & 0.32847 & 0.83558 & -0.0482 & 17.057 \\
8 & 0.45987 & 0.99914 & -0.0621 & 15.014 & 0.33277 & 0.86266 & -0.0470 & 16.967 \\
9 & 0.47922 & 0.97640 & -0.0567 & 15.032 & 0.33708 & 0.83182 & -0.0459 & 17.023 \\
10 & 0.51172 & 1.13071 & -0.0518 & 14.059 & 0.13980 & 0.68940 & -0.2276 & 14.825 \\
11 & 0.57560 & 1.11817 & -0.0713 & 13.561 & 0.16161 & 0.79366 & -0.2264 & 14.570 \\
12 & 0.61086 & 1.10563 & -0.0658 & 13.516 & 0.18342 & 0.84002 & -0.2253 & 14.358 \\
13 & 0.41239 & 1.08352 & -0.0660 & 15.030 & 0.23561 & 0.77986 & -0.1207 & 16.204 \\
14 & 0.47627 & 1.05073 & -0.0854 & 14.333 & 0.25412 & 0.85302 & -0.1195 & 15.928 \\
15 & 0.51153 & 1.01794 & -0.0800 & 14.274 & 0.27264 & 0.86827 & -0.1184 & 15.747 \\
16 & 0.37225 & 1.05318 & -0.0572 & 16.242 & 0.31076 & 0.77349 & -0.0678 & 17.328 \\
17 & 0.43613 & 1.00014 & -0.0767 & 15.385 & 0.32598 & 0.81555 & -0.0667 & 17.099 \\
18 & 0.47140 & 0.94709 & -0.0713 & 15.342 & 0.34120 & 0.79969 & -0.0655 & 17.006 \\
19 & 0.43513 & 1.19344 & -0.1003 & 14.289 & 0.10552 & 0.58413 & -0.2638 & 15.179 \\
20 & 0.51493 & 1.15060 & -0.1198 & 13.780 & 0.13824 & 0.70337 & -0.2627 & 14.879 \\
21 & 0.56611 & 1.10776 & -0.1143 & 13.708 & 0.17097 & 0.76470 & -0.2615 & 14.605 \\
22 & 0.33580 & 1.11213 & -0.1078 & 15.389 & 0.20133 & 0.67459 & -0.1569 & 16.486 \\
23 & 0.41560 & 1.04904 & -0.1272 & 14.625 & 0.23076 & 0.76273 & -0.1557 & 16.126 \\
24 & 0.46678 & 0.98595 & -0.1218 & 14.505 & 0.26019 & 0.79296 & -0.1546 & 15.846 \\
25 & 0.29567 & 1.04767 & -0.0924 & 16.791 & 0.27648 & 0.66822 & -0.1040 & 17.550 \\
26 & 0.37547 & 0.96433 & -0.1118 & 15.815 & 0.30262 & 0.72526 & -0.1029 & 17.204 \\
27 & 0.42665 & 0.88099 & -0.1064 & 15.680 & 0.32875 & 0.72438 & -0.1017 & 16.980 \\
\hline
\end{tabular}


To make the comparison more intuitive, comparison diagrams were drawn, as shown in Figures 4-7. As can be seen from Table 13, when every three groups are taken as a unit, only the velocity of the hot air is different. When taking every nine groups as a unit, the difference is the initial moisture. When all 27 groups are compared as units, the difference is relative humidity. Therefore, every three data points were taken as a comparison group to obtain the influence of the velocity of the hot air on each coefficient; every nine data points were taken as a comparison group to obtain the influence of the initial moisture of the rice on each coefficient; and all 27 data points were taken as a comparison group to obtain the influence of the relative humidity of hot air on each coefficient.

It can be seen from Figure 4 that the $k$ value affected by tempering was more sensitive to the velocity of the hot air through the comparison of every three data points. According to the comparison of every nine data points, with the increase in the initial moisture content of the rice, the $k$ value affected by tempering decreased by about $0.05-0.1$, while the $k$ value without the influence of tempering increased by about 0.05 , indicating that the increase in the initial moisture content of the rice weakened the effect of the $k$ value on the drying process. The effect of tempering on high moisture content rice was weaker than that on low moisture content rice. Through the comparison of all 27 data points, it was found that with the increase in the relative humidity of the hot air, the $k$ values with and without the influence of tempering decreased slightly, indicating that the increase of the relative humidity of the hot air tends to weaken the effect of the tempering process.

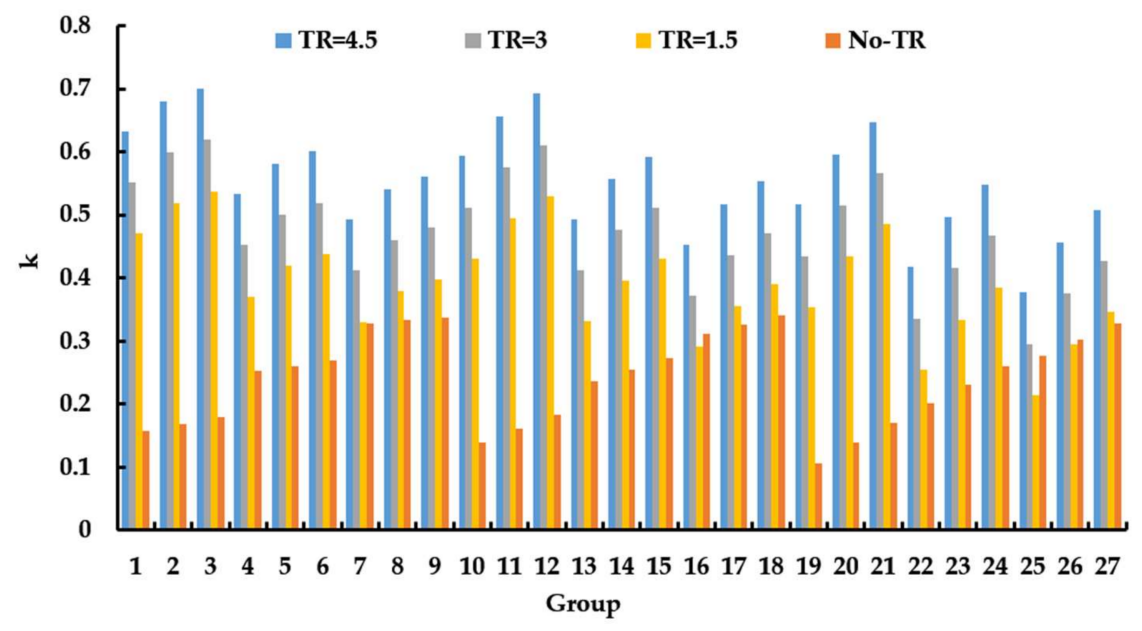

Figure 4. Comparison of the coefficient $k$ of the two models.

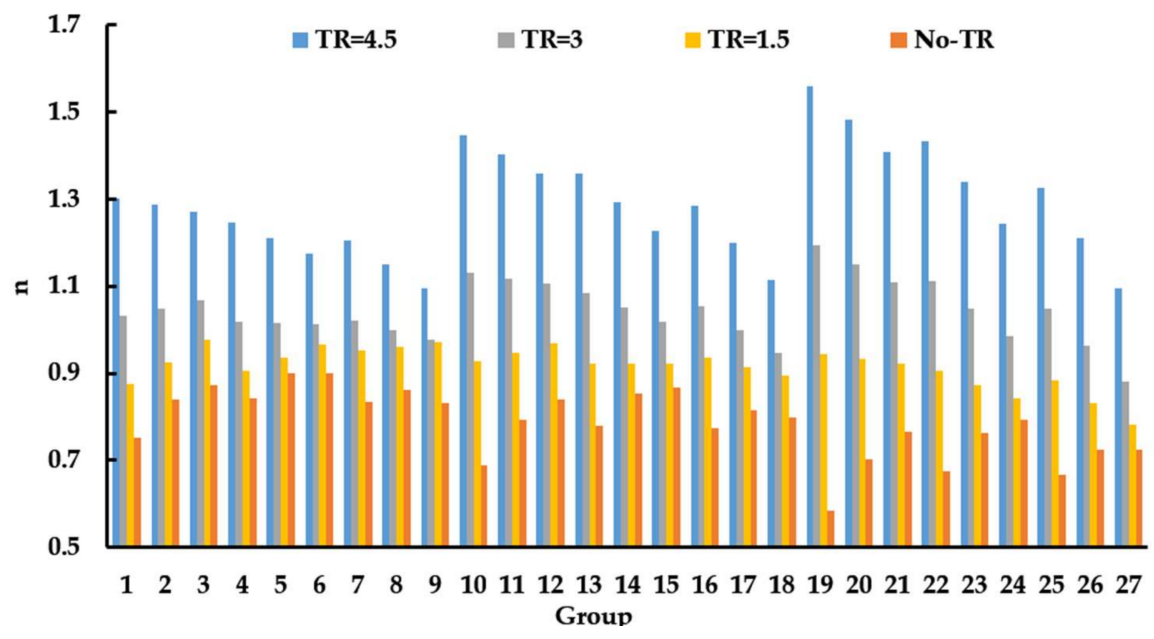

Figure 5. Comparison of the coefficient $n$ of the two models. 


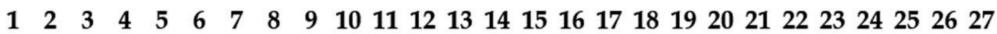

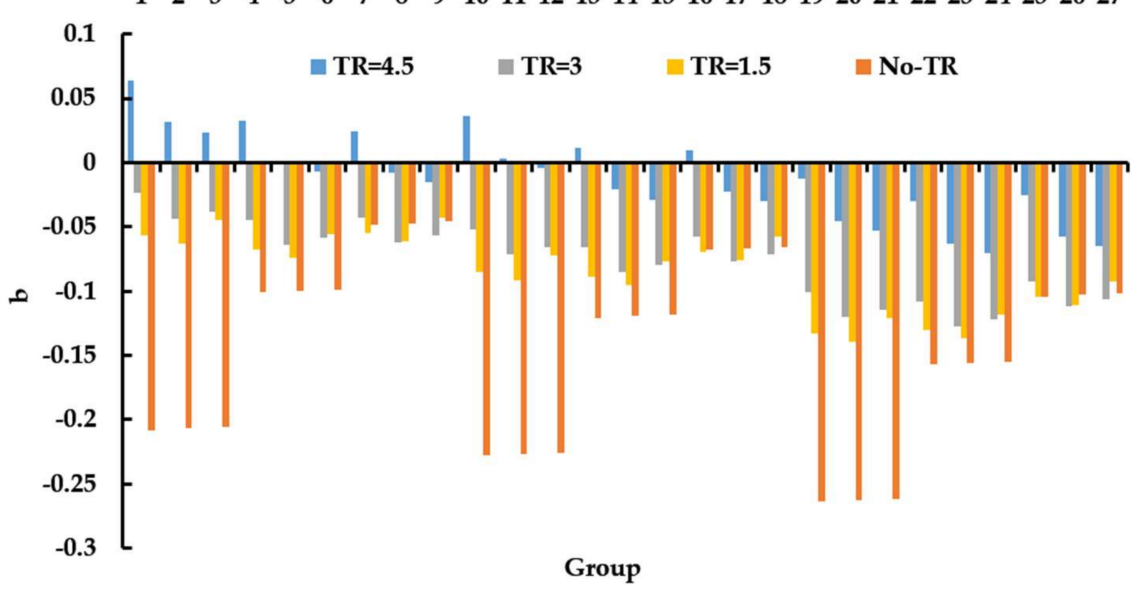

Figure 6. Comparison of the coefficient $b$ of the two models.

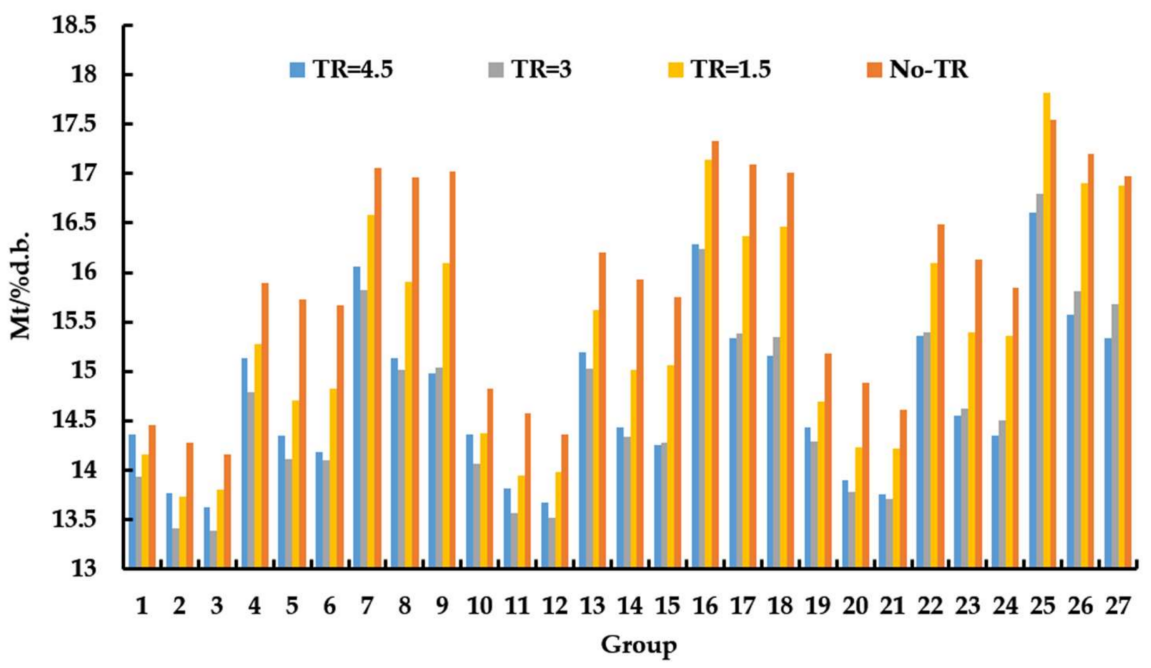

Figure 7. Comparison of moisture calculated by the two models.

Figure 5 shows that through the comparison of every three data points, it was found that the characteristics of the influence of the velocity of the hot air on the $n$ value change. When the tempering ratio was 1.5 and the relative humidity of the hot air was relatively low $(50 \%)$, the $n$ value increases with the increase of the velocity of the hot air. When the initial moisture of the rice and the relative humidity of the hot air increased, the $n$ value showed a negative correlation with the velocity of the hot air, because the desorption equilibrium temperature decreased with the increase of the initial moisture of the rice. When the tempering ratio was 3 or 4.5 , the velocity of the hot air and the $n$ value showed a negative correlation, indicating that a higher tempering ratio would hinder the drying process because too long a tempering time would lead to the occurrence of rice adsorption. Through the comparison of every nine data points, it was found that the $n$ value decreased with an increase in the initial moisture content of the rice, and that the phenomenon was more obvious with an increased tempering ratio; the reason was the same as that mentioned before. Through the comparison of all 27 data points, it was found that an increase in the relative humidity of the hot air led to an increase in the $n$ value. The main reason was that with the increase in the relative humidity of the hot air, the desorption equilibrium temperature of the rice kept increasing, which led to the slow increase of the $A T$ value and the increase of the $n$ value.

According to the AT-MR model, the $b$ value is the slope of the linear component of the AT-MR curve. Figure 6 shows that through the comparison of every three data points, it 
was found that the influence of the velocity of the hot air on the $b$ value was not obvious without the influence of tempering. In the case of the influence of tempering, the larger the tempering ratio, the more obvious the negative correlation between the velocity of the hot air and the $b$ value, indicating that the existence of the tempering process enhanced the influence of the velocity of the hot air on the $b$ value. Through the comparison of every nine data points, it was found that the $b$ value had a step change with the increase in the initial moisture content of rice without the influence of tempering. When the tempering ratio was 1.5 or 3 , the change in the $b$ value was not obvious. When the tempering ratio was 4.5 , the $b$ value decreased slightly, indicating that the existence of the tempering process weakened the linearity and made the AT-MR curve closer to the exponential relationship. Through the comparison of all 27 data points, it was found that when the tempering ratio did not exceed 3 , the $b$ value was relatively stable.

As can be seen from Figure 7, the dry basis moisture of rice without the influence of tempering was the highest, followed by the tempering ratio of 1.5. The dry basis moisture of rice was very close when the tempering ratio was 3 or 4.5, indicating that when the tempering ratio reached 3 , it was close to the optimal tempering ratio. If the tempering ratio was increased further, drying efficiency would not be improved. Through the comparison of every three data points, it was found that in the case of no tempering effect, the increase of the velocity of the hot air would accelerate the decrease in the moisture content of the rice. In the case of the tempering effect, when the velocity of the hot air changed from $0.5 \mathrm{~m} \mathrm{~s}^{-1}$ to $0.6 \mathrm{~m} \mathrm{~s}^{-1}$, the dry basis moisture content of the rice decreased rapidly, while when the velocity of the hot air changed from $0.6 \mathrm{~m} \mathrm{~s}^{-1}$ to $0.7 \mathrm{~m} \mathrm{~s}^{-1}$, the dry basis moisture content of the rice decreased slowly. This indicates that the tempering process reduces the velocity of hot air necessary for rice drying. In practical application, too high of a tempering ratio will prolong the drying time and the rice will re-absorb moisture, resulting in wasted energy. Therefore, in the rice drying operations, the tempering ratio should not exceed three.

\section{Conclusions}

In this study, the mathematical model of the relationship between drying accumulated temperature and moisture ratio of rice was established, and the results of two experiments with and without the tempering process were fitted. The results of the two kinds of fitting were compared and analyzed, and the optimal tempering ratio suitable for the drying operation of high-quality indica rice was obtained. During the research process, it was found that:

1. The relationship between the drying accumulated temperature and the moisture ratio of rice was exponential, which made it possible to establish a mathematical model. Seven existing mathematical drying models were used to fit the non-tempering test results. After selecting the model with the best fitting degree, the model was reconstructed. The reconstructed model was named the AT-MR model.

2. The AT-MR model was used to fit the test data both with tempering and without tempering, and the new evaluation parameters of the two model coefficients were obtained, as follows; Non-tempering test: $R^{2}=0.998615-0.999964, \chi^{2}\left(10^{-4}\right)=0.0280372-$ 1.408121, and RMSE $\left(10^{-4}\right)=0.0227802-1.106381$; Tempering test: $R^{2}=0.997548$ $0.999979, \chi^{2}\left(10^{-4}\right)=0.016273-2.0163$, and RMSE $\left(10^{-4}\right)=0.014239-1.6979$. Thus, the AT-MR model had high accuracy and achieved good predictive performance.

3. The influence of the tempering process on the rice drying process was analyzed by comparing the AT-MR model fitting results of the non-tempering test (our previous experiment) and the tempering test (the experiment in this study). The results showed that the optimal tempering ratio was effectively three under the conditions of regular hot air intermittent drying.

4. In our future research, we plan to model the batch drying process of rice in order to explore the changes in various indexes of rice during actual drying operations. 
Author Contributions: Conceptualization, Y.J. and Z.Z.; methodology, Y.J.; software, J.Y.; validation, Y.J., J.Y.; formal analysis, H.X.; investigation, Y.J.; resources, Y.J.; data curation, H.X.; writing-original draft preparation, Y.J.; writing-review and editing, Z.Z.; supervision, Z.Z.; project administration, Y.J.; funding acquisition, Y.J. All authors have read and agreed to the published version of the manuscript.

Funding: This research was funded by Academy of National Food and Strategic Reserves Administration, grant number JY2005. The APC was funded by JY2005.

Institutional Review Board Statement: Not applicable.

Informed Consent Statement: Not applicable.

Data Availability Statement: Not applicable.

Acknowledgments: We thank the reviewers for their valuable suggestions that helped improve the quality of the manuscript.

Conflicts of Interest: The authors declare no conflict of interest.

\section{References}

1. Lamidi, R.O.; Jiang, L.; Pathare, P.B.; Wang, Y.D.; Roskilly, A.P. Recent advances in sustainable drying of agricultural produce: A review. Appl. Energy 2019, 233-234, 367-385. [CrossRef]

2. Tanaka, F.; Tanaka, F.; Tanaka, A.; Uchino, T. Mathematical modelling of thin-layer drying according to particle size distribution in crushed feed rice. Biosyst. Eng. 2015, 136, 87-91. [CrossRef]

3. Jin, Y.; Wong, K.W.; Yang, D.; Zhang, Z.; Wu, W.; Yin, J. A neural network model used in continuous grain dryer control system. Dry. Technol. 2021, 8, 1-22. [CrossRef]

4. Wang, N.; Brennan, J.G. A mathematical model of simultaneous heat and moisture transfer during drying of potato. J. Food Eng. 1995, 24, 47-60. [CrossRef]

5. Franco, C.M.R.; de Lima, A.G.B.; Farias, V.S.O.; da Silva, W.P. Modeling and experimentation of continuous and intermittent drying of rough rice grains. Heat Mass Transf. 2019, 56, 1003-1014. [CrossRef]

6. Rufino Franco, C.M.; Barbosa de Lima, A.G.; de Oliveira Farias, V.S.; Machado, E.A. Intermittent Drying of Rice Grains with Husk: Modelling and Experimentation. Diffus. Found. 2020, 25, 9-36. [CrossRef]

7. Ertekin, C.; Firat, M.Z. A comprehensive review of thin-layer drying models used in agricultural products. Crit. Rev. Food Sci. Nutr. 2017, 57, 701-717. [CrossRef]

8. PAGE, G.E. Factors Influencing the Maximum Rates of Air Drying Shelled Corn in Thin Layers. Ph.D. Thesis, Purdue University, Ann Arbor, MI, USA, 1949.

9. Lewis, W.K. The Rate of Drying of Solid Materials. Indian Chem. Eng. 1921, 13, 427-432. [CrossRef]

10. Midilli, A.; Kucuk, H.; Yapar, Z. A New Model for Single-layer Drying. Dry. Technol. 2002, 20, 1503-1513. [CrossRef]

11. Prakash, B.; Siebenmorgen, T.J. Single-parameter Thin-layer Drying Equations for Long-grain Rice. Trans. ASABE 2018, 61, 733-742. [CrossRef]

12. Chen, J.; Wu, W.; Cheng, R.; Jin, Y.; Liu, Z. Optimization of hot air drying process of corn using genetic algorithm and response surface methodology. Int. J. Food Prop. 2020, 23, 753-764. [CrossRef]

13. Alves Pereira, J.C.; da Silva, W.P.; Gomes, J.P.; Queiroz, A.J.M.; de Figueirêdo, R.M.F.; de Melo, B.A.; Santiago, Â.M.; de Lima, A.G.B.; de Macedo, A.D.B. Continuous and Intermittent Drying of Rough Rice: Effects on Process Effective Time and Effective Mass Diffusivity. Agriculture 2020, 10, 282. [CrossRef]

14. Kucuk, H.; Midilli, A.; Kilic, A.; Dincer, I. A Review on Thin-Layer Drying-Curve Equations. Dry. Technol. 2014, 32, 757-773. [CrossRef]

15. Ghasemi, A.; Sadeghi, M.; Mireei, S.A. Multi-stage intermittent drying of rough rice in terms of tempering and stress cracking indices and moisture gradients interpretation. Dry. Technol. 2017, 36, 109-117. [CrossRef]

16. Zhou, X.; Liu, L.; Fu, P.; Lyu, F.; Zhang, J.; Gu, S.; Ding, Y. Effects of infrared radiation drying and heat pump drying combined with tempering on the quality of long-grain paddy rice. Int. J. Food Sci. Technol. 2018, 53, 2448-2456. [CrossRef]

17. Aquerreta, J.; Iguaz, A.; Arroqui, C.; Vírseda, P. Effect of high temperature intermittent drying and tempering on rough rice quality. J. Food Eng. 2007, 80, 611-618. [CrossRef]

18. Tohidi, M.; Sadeghi, M.; Torki-Harchegani, M. Energy and quality aspects for fixed deep bed drying of paddy. Renew. Sustain. Energy Rev. 2017, 70, 519-528. [CrossRef]

19. Golmohammadi, M.; Assar, M.; Rajabi-Hamaneh, M.; Hashemi, S.J. Energy efficiency investigation of intermittent paddy rice dryer: Modeling and experimental study. Food Bioprod. Process. 2015, 94, 275-283. [CrossRef]

20. Cihan, A.; Kahveci, K.; Hacıhafızoğlu, O. Modelling of intermittent drying of thin layer rough rice. J. Food Eng. 2007, 79, 293-298. [CrossRef]

21. Dong, R.; Lu, Z.; Liu, Z.; Koide, S.; Cao, W. Effect of drying and tempering on rice fissuring analysed by integrating intra-kernel moisture distribution. J. Food Eng. 2010, 97, 161-167. [CrossRef] 
22. Wu, Y.; Wu, W.; Han, F.; Zhang, Y.; Xu, Y. Intelligent Monitoring and Control of Grain Continuous Drying Process Based on Multi-parameter Corn Accumulated Temperature Model. In Proceedings of the 2017 International Conference on Smart Grid and Electrical Automation, Changsha, China, 27-28 May 2017; pp. 77-80. [CrossRef]

23. Jin, Y.; Wong, K.W.; Wu, Z.; Qi, D.; Wang, R.; Han, F.; Wu, W. Relationship between accumulated temperature and quality of paddy. Int. J. Food Prop. 2019, 22, 19-33. [CrossRef]

24. Hu, X.W.; Fan, Y.; Baskin, C.C.; Baskin, J.M.; Wang, Y.R. Comparison of the effects of temperature and water potential on seed germination of Fabaceae species from desert and subalpine grassland. Am. J. Bot. 2015, 102, 649-660. [CrossRef]

25. Liu, D.; Xin, L.I.; Zheng, H.; Wang, Z.H.; University, N.A. Analysis on Changes of Earth Temperature and Spring Maize Sowing Time in Second Accumulated Temperature of Heilongjiang Province. J. Maize Sci. 2016, 24, 103-106. [CrossRef]

26. Sun, L.L.; Li-Li, X.U.; Yuan-Peng, D.U.; Zhai, H. The relationship of effective accumulated temperature and bud burst in grapevine. Plant Physiol. J. 2016, 52, 1263-1270. [CrossRef]

27. Zhao, D.; Wu, S. Spatial and temporal variability of key bio-temperature indicators on the Qinghai-Tibetan Plateau for the period 1961-2013. Int. J. Climatol. 2016, 36, 2083-2092. [CrossRef]

28. Liu, Y.; Hou, P.; Xie, R.; Hao, W.; Li, S.; Mei, X. Spatial Variation and Improving Measures of the Utilization Efficiency of Accumulated Temperature. Crop Sci. 2015, 55, 1806-1807. [CrossRef]

29. Ni, X.; Gunawan, G.; Brown, S.L.; Sumner, P.E.; Ruberson, J.R.; Buntin, G.D.; Holbrook, C.C.; Lee, R.D.; Streett, D.A.; Throne, J.E. Insect-Attracting and Antimicrobial Properties of Antifreeze for Monitoring Insect Pests and Natural Enemies in Stored Corn. J. Econ. Entomol. 2008, 101, 631. [CrossRef] [PubMed]

30. Синельшков, B.B. General Agricultural Meteorology; Higher Education Press: Beijing, China, 1959.

31. Agrawal, K.K.; Clary, B.L.; Nelson, G.L. Investigation into the Theories of Desorption Isotherms for Rough Rice and Peanuts; Blackwell Publishing Ltd.: Hoboken, NJ, USA, 1971; Volume 36, pp. 919-924. [CrossRef]

32. Li, X. Fiting Parameters of EMC/ERH Model for Chinese Rough Rice. J. Chin. Cereals Oils Assoc. 2010, 25, 1-8. 